\title{
European Union Policies and Civil Drones
}

\author{
Virginia Santamarina Campos
}

\begin{abstract}
This chapter provides an analysis of the drone policies in the European Union, divided into types of actors (manufacturers, operators, and pilots), drones (more or less than $150 \mathrm{~kg}$, risk classification), licenses, and insurance (depending on the drone and the activity), at the European level. All these policies affect producers and operators. The problems related to licenses, the type of drone and activity, and the chance of obtaining insurance will have an impact on the development of the drone industry in the future. According to the European Union, there are two main current recommendations when regulating drone use: (a) distinguish not by mass but by risk (although mass is a parameter to bear in mind) and (b) do not distinguish the use/mission of the drone, since, depending on the drone, the risks can be the same for both professional and hobby/leisure use.
\end{abstract}

\section{Introduction}

Many proposals concerning how to classify drones, RPASs (remotely piloted aircraft systems), UASs (unmanned aircraft systems), or UAVs (unmanned aerial vehicles) can be found in specific literature, and a comparison of these can be consulted in, for example, Hassanalian and Abdelkefi (2017). A basic classification first of all distinguishes the mission of the drone: civilian or military. Of course, one question immediately arises in both cases: why employ a drone? The advantages for both civilian and military missions are quite obvious: the "flying robots" are unmanned. Thus, for example in military operations, the injury/loss of a pilot can be avoided. However, this is also true for civilian purposes. The inspection of a bridge can be performed by a drone (RPAS), and no engineer has to climb or abseil for monitoring purposes. Deployment and maintenance are also cheaper, which is another benefit when drones are employed. This has made basic and applied research in the last years attractive for both types of mission, civilian and military.

\footnotetext{
V. Santamarina Campos $(\bowtie)$

Universitat Politècnica de València, Valencia, Spain

e-mail: virsanca@upv.es

(C) The Author(s) 2018 
As a consequence, great technological progress has been achieved, leading to the successful introduction of drones into the mass market with low prices and their use in different sectors, such as leisure, cultural heritage, industrial inspections, agriculture, emergencies, surveillance, transport, health, and so on.

This is reflected in the fact that the drone market has increased exponentially in the last years. As shown in Fig. 1, not only manufacturers but also services compound this sector, in which manufacturers and components comprised $45 \%$ in 2016 (platforms $29 \%$ and components and systems 16\%), while related activities included the remaining $65 \%$, such as services (20\%), universities and research programmes $(10 \%)$, software $(7 \%)$, news/media/blogs $(6 \%)$, coalitions/organizations/ initiatives $(5 \%)$, conferences and events $(3 \%)$, operator marketplaces $(2 \%)$, drone insurance $(2 \%)$, and user groups/networks $(1 \%)$.

On the other hand, new applications can generate a larger market in the coming years, in which the business opportunities can generate a value of more than 127 million dollars (Table 1).

However, this situation entails a legal vacuum, whereby drones fall outside the aviation rules if their weight is less than $150 \mathrm{~kg}$ (Regulation CE no. 216/2008), and in this case each Member State of the European Agency of Safety Aviation (EASA) has to define its own parameters (EASA 2015, 2017).

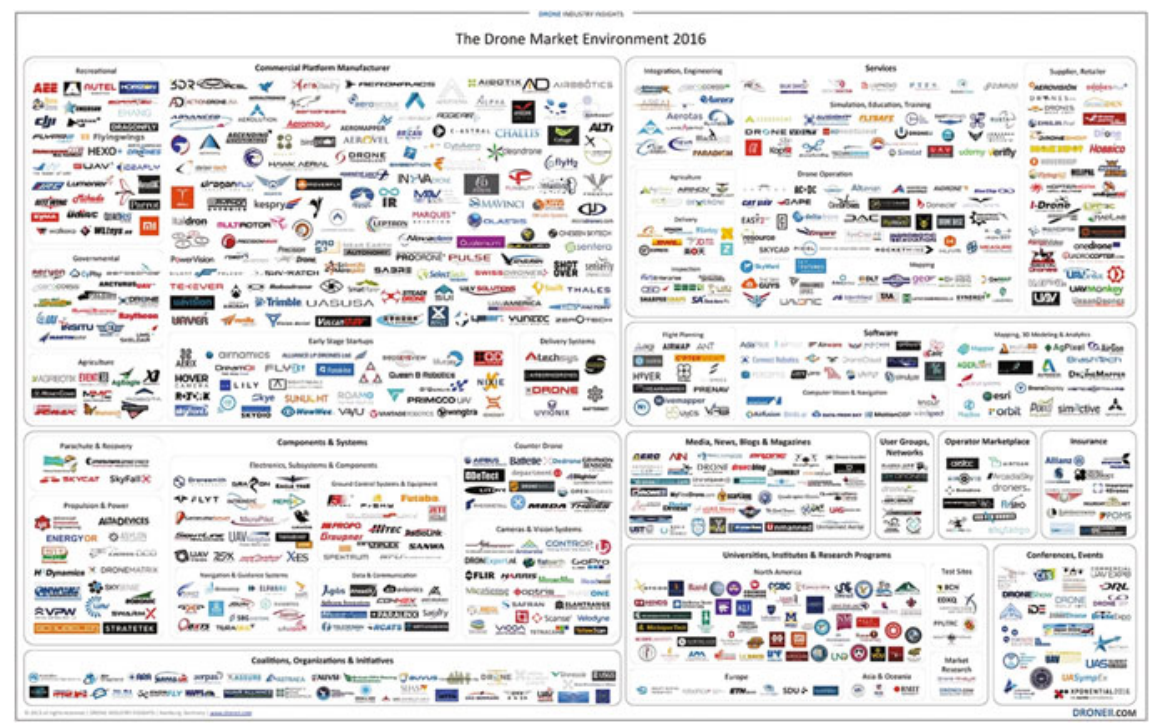

Fig. 1 The drone market environment map 2016, with permission of the company. Source Droneii (2016) 
Table 1 Value of drone powered solutions' addressable industries: global view (\$ bn)

\begin{tabular}{l|r}
\hline & 2015 \\
\hline Infrastructure & 45.2 \\
\hline Transport & 13.0 \\
\hline Insurance & 6.8 \\
\hline Media and Ent. & 8.8 \\
\hline Telecommunication & 6.3 \\
\hline Agriculture & 32.4 \\
\hline Security & 10.5 \\
\hline Mining & 4.3 \\
\hline Total & 127.3 \\
\hline
\end{tabular}

Source PwC (2016)

\section{Actors}

According to the EASA (2015, 2017), different stakeholders are affected by civil drones: national aviation authorities, the aviation industry, air navigation service providers (ANSPs), airspace users (or pilots), manufacturers, drone operators, and the general public.

In our research five main parties should be taken into account:

- Drone manufacturers: that is, the producers of the final product. They could be from the EU or from a non-EU country. Nevertheless, all of them should comply with the EU country requirements.

- Operators: people holding a license to navigate a drone as well as people who give training to other pilots. That is, their drone use has purely a professional/ commercial purpose.

- Pilots/users: they can also be operators when there is professional/commercial use of the drone, but they might also hold no license if the drone weight is below a specific value and is used just for hobby/leisure purposes.

- Members of the general public: their safety and security can be affected by a drone. The main concerns for people are related to safety, the environment, privacy, and data protection (Smith 2014).

- The economy: businesses that may include the use of UASs in their business model to lower costs and/or add new innovative services.

In the case of civil drones weighing less than $150 \mathrm{~kg}$, it is apparent that different European countries regulate the activity of these actors differently. For example, in 2016 the use of camera drones was made illegal in Sweden by its Supreme Administrative Court unless the users have been granted a special surveillance permit (BBC 2016), even though in 2014 more than 1000 permits were issued for the use of camera drones for commercial purposes in this country. 


\section{European Policies: A Brief Review}

The EASA (2015: 4) provided a regulatory definition of a drone, which could be very useful in the case of courts' discrepancies:

Drone shall mean an aircraft without a human pilot on board, whose flight is controlled either autonomously or under the remote control of a pilot on the ground or in another vehicle.

Moreover, a consultation for this Advance Notice of Proposed Amendment (A-NPA) (EASA 2015) was open until 25 September 2015. This proposal basically distinguished three categories of drones depending on the risks associated with people and property: open (low risk), specific (medium risk), and certified (high risk) (Fig. 2).

- 'Open' category (low risk): this could include indoor drones

- 'Specific operation' category (medium risk): a manual of operations with a list of the risk mitigation measures will be required

- 'Certified' category (higher risk): a licence and approval of maintenance, operations, training, and so on will be required.

Following that proposal, a new one was presented by the EASA in (2017) to create a regulatory framework for the operation of drones in the case of the open and specific categories. This draft was available for enquiry until 15 September 2017. All this information will be used by the EASA to elaborate a comment review document (CRD).

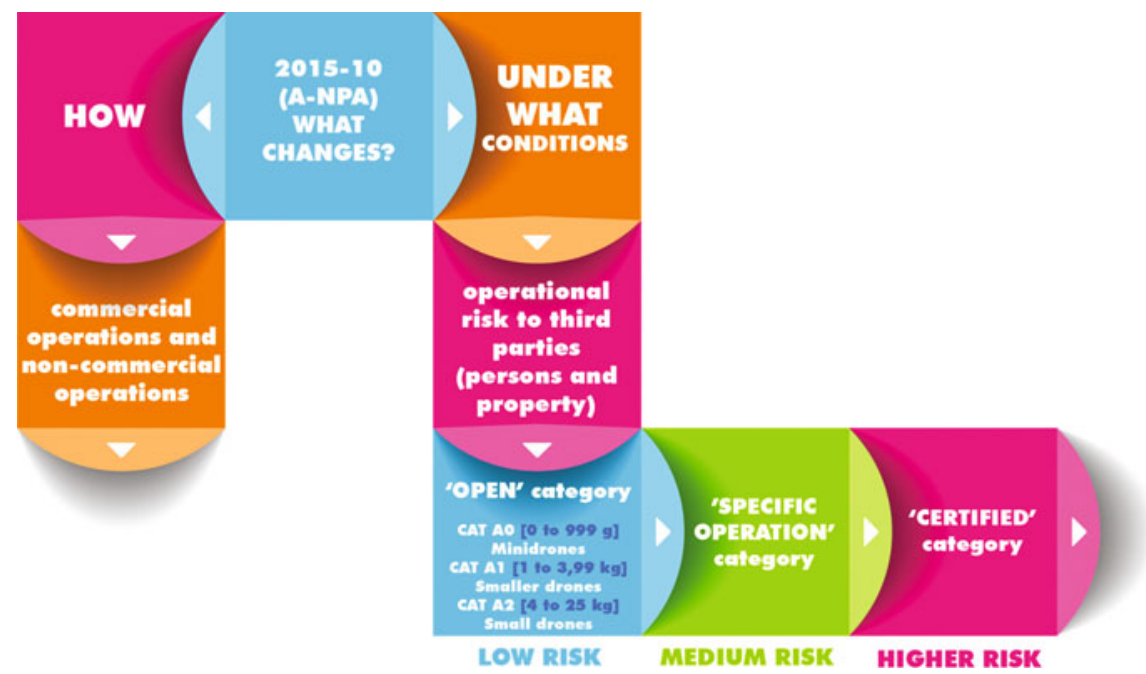

Fig. 2 Changes proposed by the EASA. Source own elaboration adapted from the EASA 
The European Council and the Parliament are continuing to work together to provide a common regulatory framework to support the European competitiveness and leadership in the drone sector to deliver new employment and business opportunities and, at the same time, to respect safety, privacy, and the environment, as stated in the Warsaw Declaration (EASA 2016).

This new regulatory framework is supposed to be presented to the European Commission by the end of 2017, so at present licences and assurances and types of activities and drones are still regulated differently by the European countries, as we can see in the chapters "Spain-UK-Belgium Comparative Legal Framework" and "Legal and Ethical Recommendations".

However, some countries have started to change their own regulations. For example, in the UK, even with the "Brexit" process pending and without knowing whether that future framework will be applied in this country, in 2017 the Government announced a plan to require the owners of drones weighing more than $250 \mathrm{~g}$ to register their devices (TechCrunch 2017). Moreover, a new drone safety awareness test will have to prove that the drone operators understand the relevant safety, security, and privacy regulations.

\section{Insurance Regulations and Drones in the European Union}

The European Insurance Regulation on the insurance requirements for air carriers and aircraft operators (European Commission 2004) requires them to be insured with some exceptions: among them, these include model aircrafts with a maximum take-off mass (MTOM) of less than $20 \mathrm{~kg}$ when used for non-commercial purposes. However, even though there is no definition of what a model aircraft is for the purposes of the European Insurance Regulation, it is assumed that it encompasses drones. Therefore, an operator is exempt from the insurance requirement if he/she uses a drone weighing less than $20 \mathrm{~kg}$ for non-commercial purposes (Farrar's Building 2016).

Moreover, article 3 of this Regulation provides the following definition of an aircraft operator:

... means the person or entity, not being an air carrier, who has continual effective disposal of the use or operation of the aircraft; the natural or legal person in whose name the aircraft is registered shall be presumed to be the operator, unless that person can prove that another person is the operator.

Furthermore, a commercial operation is defined as "an operation for remuneration and/or hire". Therefore, any purpose that could generate income must be a commercial purpose and require the drone operator to hold insurance; in this sense most commercial uses will be obvious if the drone is being used by a company or organization (Farrar's Building 2016). 


\section{Conclusions}

The drone market has increased exponentially in the last years, and many involved parties depend on drone activities: national aviation authorities, the aviation industry, the general public, manufacturers and operators of drones, air navigation service providers (ANSPs), and airspace users (or pilots). However, at present, without a common regulatory framework, different European countries regulate the activity of these actors in different ways. Those uncertainties hamper the economic development of this big European market.

While in the case of professional and commercial activities the rules seem to be easier to approach (as, for example, in the case of insurance for drones), the regulation of recreational activities might be quite difficult. For this reason the European Agency of Safety Aviation (EASA) is continuing to work to provide a common regulatory framework to support the European competitiveness and leadership in the drone sector, to deliver new employment and business opportunities, and, at the same time, to give other European citizens who could be affected by drones' activity more safety and security.

\section{References}

BBC (2016) Sweden bans cameras on drones. http://www.bbc.com/news/technology-37761872. Accessed 18 August 2017

Droneii (2016) The drone market environment map 2016. https://www.droneii.com/drone-marketenvironment-map-2016. Accessed 7 August 2017

EASA (2015) Advance notice of proposed amendment 2015-10, A-NPA. https://www.easa. europa.eu/system/files/dfu/A-NPA\%202015-10.pdf. Accessed 6 July 2017

EASA (2016) Warsaw declaration: drones as a leverage for jobs and new business opportunities. https://ec.europa.eu/transport/sites/transport/files/drones-warsaw-declaration.pdf. Accessed 18 August 2017

EASA (2017) Notice of proposed amendment 2017-05, B-NPA. Introduction of a regulatory framework for the operation of drones, unmanned aircraft system operations in the open and specific category. https://www.easa.europa.eu/system/files/dfu/NPA\%202017-05\%20\%28B\% 29.pdf. Accessed 18 August 2017

European Commission (2004) Regulation (EC) no. 785/2004 of the European Parliament and of the Council of 21 April 2004 on insurance requirements for air carriers and aircraft operators. Available via EURLEX. http://eur-lex.europa.eu/legal-content/EN/TXT/HTML/?uri=CELEX: 32004R0785\&from=EN. Accessed 21 August 2017

Farrar's Building (2016) Drones and insurance. http://www.farrarsbuilding.co.uk/insurance-lawupdate-december-2016/\#_ftn2. Accessed 19 August 2017

Hassanalian M, Abdelkefi A (2017) Classifications, applications, and design challenges of drones: a review. Prog in Aerosp Sci 91(May):99-131

PwC (2016) Clarity from above. PwC global report on the commercial applications of drone technology. http://pwc.blogs.com/files/clarity-from-above-pwc.pdf. Accessed 7 August 2017

Smith ML (2014) Regulating law enforcement's use of drones: the need for state legislation. Harv J Legis 52:423-455. https://doi.org/10.2139/ssrn.2492374

TechCrunch (2017) Drone registration coming to the UK. https://techcrunch.com/2017/07/22/ drone-registration-coming-to-the-uk/. Accessed 18 August 2017 
Open Access This chapter is licensed under the terms of the Creative Commons Attribution 4.0 International License (http://creativecommons.org/licenses/by/4.0/), which permits use, sharing, adaptation, distribution and reproduction in any medium or format, as long as you give appropriate credit to the original author(s) and the source, provide a link to the Creative Commons license and indicate if changes were made.

The images or other third party material in this chapter are included in the chapter's Creative Commons license, unless indicated otherwise in a credit line to the material. If material is not included in the chapter's Creative Commons license and your intended use is not permitted by statutory regulation or exceeds the permitted use, you will need to obtain permission directly from the copyright holder.

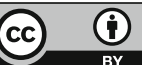

